\title{
Titanium stable isotopes and the crust-mantle system: what have we learned?
}

\author{
MARC-ALBAN MILLET ${ }^{1}$, LIAM HOARE ${ }^{1}$, MARTIJN \\ KLAVER $^{1}$ AND NIKITHA SAJI $^{2}$
}

${ }^{1}$ Cardiff University

${ }^{2}$ Centre for Star and Planet Formation, Globe Institute, University of Copenhagen

Presenting Author: milletm@cardiff.ac.uk

Despite being one of the more recently available stable isotope systems for study, the stable isotope composition of titanium (Ti) has received considerable attention over the last few years. This recent interest in titanium stable isotopes is in contrast to the longstanding use of its concentration in rocks and minerals as a tracer of magmatic processes. As a refractory, highly insoluble and single valency element, Ti displays a simpler chemical behaviour than other novel stable isotope system. It therefore offers the promise of a less complex framework of interpretation hinging around the utilisation of the oxide-melt equilibrium, which controls the budget of $\mathrm{Ti}$ in magmatic systems.

These properties make Ti isotopes a potentially powerful tool to study the evolution of the crust-mantle system throughout Earth history. Indeed, Ti isotopes have been used to argue for an early start to plate tectonics, potentially soon after the HadeanArchean boundary. However, these interpretations currently stand at odds with information from other more accepted geochemical tracers. As such, improved determination of the Ti isotope composition of key terrestrial reservoirs as well as more in depth understanding of the exact mechanics of $\mathrm{Ti}$ isotope fractionation in magmatic and detrital sediments is warranted.

Here, we will discuss the progress made and remaining unknowns on these questions. Specifically, we will focus on the outstanding limitations in the use of Ti isotopes that come from i) the uncertainty in the value of the chondritic reservoir, for which available estimates cover a range of c. $0.08 \%$, outside of analytical uncertainty; ii) the lack of definition of the mechanics of isotope fractionation during magma evolution and especially its relationship with composition of the melts and associated crystal cargo, and the coordination of Ti within them; and finally iii) the potential for $\mathrm{Ti}$ isotope fractionation during sedimentary processes. 